\title{
Open surgical thoracoabdominal aortic aneurysm repair: The Heidelberg experience
}

Sabreen Mkalaluh, MD, Marcin Szczechowicz, MD, Bashar Dib, MD, Alexander Weymann, MD, PhD, Gabor Szabo, MD, PhD, and Matthias Karck, MD, PhD

\section{ABSTRACT}

Objective: Open surgical repair of thoracoabdominal aortic aneurysm remains an important treatment option and continues to be challenging. The objective of this study was to investigate the results after open repair of thoracoabdominal aortic aneurysms in a contemporary non-high-volume center collective.

Methods: A total of 38 patients underwent operation for thoracoabdominal aortic aneurysm between August 2007 and April 2017. Patients had aortic aneurysm and chronic aortic dissection. The majority of patients had already undergone previous aortic interventions.

Results: The mean age was $54.4 \pm 13.4$ years (range, 29-72.5 years), and 22 patients $(57.9 \%)$ were female. Most commonly, patients $(57.9 \%)$ presented with Crawford type II aneurysms. The mean cardiopulmonary bypass time was $159 \pm 65$ minutes. The operative mortality was $10.5 \%(\mathrm{n}=4)$. The paraplegia rate and the incidence of stroke were $7.9 \%(\mathrm{n}=3)$. Postoperatively, 4 patients $(10.5 \%)$ required temporary hemodialysis. In 4 patients $(10.5 \%)$, reexploration due to bleeding was necessary. Sepsis developed in 4 patients (10.5\%). Preoperative renal insufficiency was identified as a predictor of mortality. The patients were discharged from the hospital after a median length of stay of 21.5 days. The 1-year survival was $83 \%$.

Conclusions: Despite the invasiveness of open thoracoabdominal aortic repair and significant risk of major complications, surgical repair can be accomplished in a non-high-volume center with acceptable results. (J Thorac Cardiovasc Surg 2018;156:2067-73)

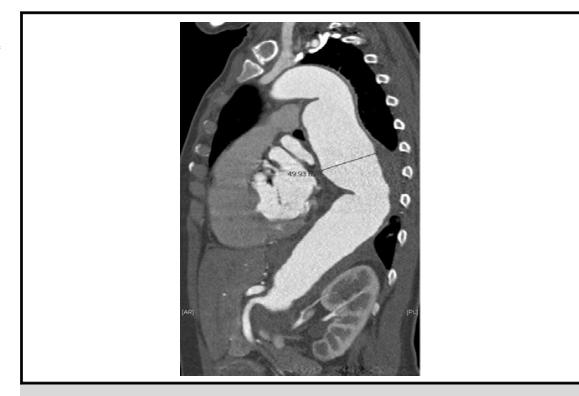

A 64-year-old female patient with Crawford type ॥I aneurysm.

\section{Central Message}

In a non-high-volume center of aortic surgery, operative mortality was $10.5 \%$ and paraplegia rate was $7.9 \%$ with an $83 \% 1$-year survival.

\section{Perspective}

We present the results of a contemporary collective of patients with TAAA undergoing open repair. The results are comparable to findings from the literature. Our results suggest that open repair of TAAA has the potential to remain standard of care, but further comparative studies with comparable treatment options (open surgical vs interventional) are needed.

See Editorial Commentary page 2074.

See Editorial page 2051.
The first successful thoracoabdominal aortic aneurysm (TAAA) repair was performed by Etheredge and colleagues in $1955 .{ }^{1}$ Today, this demanding operation continues to be challenging and remains associated with significant morbidity and mortality. The most feared postoperative

\footnotetext{
From the Department of Cardiac Surgery, Heart and Marfan Center, University of Heidelberg, Heidelberg, Germany.

Date and number of Institutional Review Board approval: S-266/2017. June 6, 2017. Received for publication Dec 19, 2017; revisions received April 24, 2018; accepted for publication May 1, 2018; available ahead of print July 3, 2018.

Address for reprints: Sabreen Mkalaluh, MD, Department of Cardiac Surgery, Heart and Marfan Center, University of Heidelberg, Im Neuenheimer Feld 110, 69120 Heidelberg, Germany (E-mail: sabreen.mkalaluh@gmx.de). $0022-5223 / \$ 36.00$

Copyright (C) 2018 by The American Association for Thoracic Surgery https://doi.org/10.1016/j.jtcvs.2018.05.081
}

complications are paraplegia and renal failure requiring hemodialysis. ${ }^{2}$ Furthermore, thoracoabdominal aortic repair is associated with remarkable early mortality. This aspect has encouraged the use of less-invasive treatment options, such as endovascular procedures and hybrid techniques. ${ }^{2,3}$ Currently, endovascular treatment is gaining increased popularity and is considered a valid treatment option

Scanning this QR code will take you to a procedural video. 


\section{Abbreviations and Acronyms \\ $\mathrm{IQR}=$ interquartile range \\ TAAA $=$ thoracoabdominal aortic aneurysm}

predominantly in cases of uncomplicated thoracic and abdominal aortic aneurysms. ${ }^{3,4}$ A number of series showed that the obviously less-invasive endovascular therapy has not significantly reduced the incidence of life-threatening events such as paraplegia or early mortality. Furthermore, the rates of reintervention seem to be higher in patients treated endovascularly., ${ }^{3,5-9}$

In view of the fact that contemporary data about outcomes of open surgical TAAA repair from non-high-volume centers are rare, in this study we analyzed the results of open TAAA repair and survival in a contemporary, high-risk patient collective in a non-high-volume aortic surgery institution.

\section{MATERIALS AND METHODS \\ Study Population}

A total of 38 patients underwent open TAAA repair between August 2007 and April 2017 in our institution. The preoperative demographic characteristics were analyzed, along with the intraoperative and postoperative early and short-term outcomes.

\section{Surgical Techniques}

We used the standardized approach for TAAA repair, which has been described in detail. ${ }^{2,10}$ All patients were operated through a left thoracoabdominal incision with a circumferential division of the diaphragm. All operations were performed using femoral-femoral cardiopulmonary bypass at permissive hypothermia. Video 1 shows a thoracoabdominal aortic repair in a 37-year-old patient with Marfan syndrome.

If aortic crossclamping of the aortic arch distal to the origin of the left carotid artery was not possible, hypothermic circulatory arrest was used. This was necessary in 6 patients. The aneurysm was replaced during sequential clamping. After opening of the abdominal aortic segment, the intestinal and renal arteries were selectively perfused with oxygenated blood. These vessels were reimplanted consecutively, together with a variable number of intercostal and lumbar arteries, in the majority of patients. In 15 patients, no intercostal or lumbar arteries were reattached. All patients received cerebrospinal fluid drainage preoperatively. Intubation was performed with a double-lumen endotracheal tube, thereby enabling collapse of the left lung during the operation. We did not use neuromonitoring with motor-evoked potentials.

\section{Statistical Analysis}

Patients were studied retrospectively. Data of the study were analyzed using SPSS, version 24.0 (IBM Corp, New York, NY) and described as continuous and categoric variables subsequently. Continuous variables are presented as mean \pm standard deviation or median (25th quartile; 75 th quartile, interquartile range [IQR]). Categoric variables are described in number and percentage forms. Preoperative and intraoperative variables were analyzed with univariate logistic regression models for identifying predictors of 30-day mortality and proportional hazard regression for identifying predictors of mortality with long-term follow-up. The odds ratio and the $95 \%$ confidence interval were given in relation to each parameter. The chi-square test was used to describe the relations between categoric variables. Survival was calculated and graphically presented by the Kaplan-Meier method. The Kaplan-Meier estimates of survivor function and corresponding $95 \%$ confidence interval were also calculated

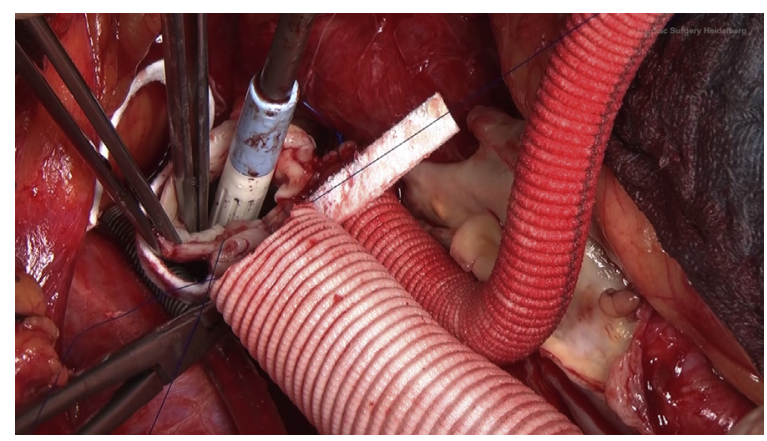

VIDEO 1. Thoracoabdominal aortic repair in a 37-year-old patient with Marfan syndrome. Video available at: https://www.jtcvs.org/article/ S0022-5223(18)31511-3/fulltext.

and presented. For the survival analysis, we used R 3.4.3 (A Language and Environment for Statistical Computing, The R Foundation for Statistical Computing, Vienna, Austria, 2017, http://www.R-project.org), with extension Survminer (Alboukadel Kassambara and Marcin Kosinski (2018). Survminer: Drawing Survival Curves using 'ggplot2'. R package version 0.4.2; https://CRAN.R-project.org/package=survminer).

\section{Definitions}

All aneurysms were categorized on the basis of Crawford's classification. Operative mortality was defined as death within 30 days after surgery or death during the original hospitalization. Postoperative respiratory failure was defined as reintubation, tracheotomy, or a need for mechanical ventilation for longer than 72 hours. Postoperative stroke, paraparesis, and paraplegia were defined as a new and permanent or temporary neurologic disability or deficit. Postoperative acute renal failure was defined as an increase of the serum creatinine level to twice its baseline value. Postoperative temporary renal failure was defined as a new necessity for dialysis during the hospital stay and as permanent terminal renal failure if dialysis was necessary at the time of discharge. The gastrointestinal complications included gastrointestinal bleeding and visceral ischemia. Redo-operation was defined as surgery on a previously operated aorta. The follow-up data were obtained by clinical visits. This study was approved by the local ethics committee of our university, medical faculty S-266/2017 (June 6, 2017).

\section{RESULTS}

\section{Preoperative Data}

The patient demographics are summarized in Table 1. Overall, the mean age at the time of TAAA repair was $54.4 \pm 13.4$ years (range, 29-72.5 years) and female patients were predominantly affected $(57.9 \%, \mathrm{n}=22)$. Crawford extent II aneurysm was the most common type $(\mathrm{n}=22,57.9 \%)$, followed by extent $\mathrm{I}(\mathrm{n}=12,31.6 \%)$. The mean diameter was $7.0 \pm 1.2 \mathrm{~cm}$ (range, $5-12 \mathrm{~cm}$ ). In 25 patients, the procedure was a redo operation, and 24 patients had chronic aortic dissection (12 patients [31.6\%] with chronic dissection type A and 12 patients [31.6\%] with chronic dissection type B). Five patients $(13.2 \%)$ had undergone endovascular interventions previously. Nine patients $(23.7 \%)$ had already experienced chronic renal failure; among them, $1(2.6 \%)$ had dialysis preoperatively. Three patients were preoperatively paraplegic as a consequence of previous open or endovascular repair elsewhere. The cause of the aortic disease was 
TABLE 1. Patient demographics

\begin{tabular}{|c|c|}
\hline Variable & Value \\
\hline Age $(y$, mean $\pm S D)$ & $54.4 \pm 13.4$ \\
\hline Male & $16(42.1 \%)$ \\
\hline BMI, $\mathrm{kg} / \mathrm{m}^{2}$ & $24.6 \pm 4.6$ \\
\hline Hypertension & $30(78.9 \%)$ \\
\hline Myocardial infarction & $1(2.6 \%)$ \\
\hline Peripheral arterial disease & $4(10.5 \%)$ \\
\hline Cerebral vascular accident & $1(2.6 \%)$ \\
\hline Paraplegia preoperatively & $3(7.9 \%)$ \\
\hline Diabetes & $1(2.6 \%)$ \\
\hline Cigarette smoking & $17(44.7 \%)$ \\
\hline Chronic renal failure & $9(23.7 \%)$ \\
\hline Chronic renal failure with hemodialysis & $1(2.6 \%)$ \\
\hline Prior type A dissection & $12(31.6 \%)$ \\
\hline Prior type B dissection & $12(31.6 \%)$ \\
\hline Previous aortic surgery & $25(66 \%)$ \\
\hline Prior endovascular repair & $5(13.2 \%)$ \\
\hline Emergency/urgent procedures & $8(21 \%) / 8(21 \%)$ \\
\hline \multicolumn{2}{|l|}{ Aortic disease } \\
\hline Connective tissue disorder & $18(47.4 \%)$ \\
\hline Degenerative chronic aneurysm & $16(42.1 \%)$ \\
\hline Inflammatory & $2(5.3 \%)$ \\
\hline Infected aortic prosthesis & $2(5.3 \%)$ \\
\hline Aortic diameter $(\mathrm{cm}$, mean $\pm \mathrm{SD})$ & $7 \pm 1.2$ \\
\hline \multicolumn{2}{|l|}{ TAAA extent } \\
\hline I & $12(31.6 \%)$ \\
\hline II & $22(57.9 \%)$ \\
\hline III & $3(7.9 \%)$ \\
\hline IV & $1(2.6 \%)$ \\
\hline \multicolumn{2}{|l|}{ No. of prior aortic surgical procedures } \\
\hline 0 & $17(44.7 \%)$ \\
\hline 1 & $16(42.1 \%)$ \\
\hline 2 & $1(2.6 \%)$ \\
\hline 3 & $4(10.5 \%)$ \\
\hline
\end{tabular}

SD, Standard deviation; BMI, body mass index; TAAA, thoracoabdominal aortic aneurysm.

diverse. A total of 18 patients $(47.4 \%)$ had connectivetissue disorders: Marfan syndrome $(\mathrm{n}=15)$, EhlersDanlos syndrome $(\mathrm{n}=2)$, Loeys-Dietz syndrome $(\mathrm{n}=1)$, and atherosclerotic aneurysm $(\mathrm{n}=16 ; 42.1 \%)$. In 2 patients $(5.3 \%)$, the cause was most likely of infectious origin (mycotic aneurysm), and in 2 patients $(5.3 \%)$, inflammatory disease of the aorta was known. The 2 patients with aortic infection had vascular prosthetic infection after open surgical TAAA repair and endovascular treatment. They were paraplegic preoperatively. Twentytwo patients $(57.9 \%)$ were treated electively, 8 patients $(21.1 \%)$ were treated urgently, and in 8 patients $(21.1 \%)$, emergency surgery was necessary.
TABLE 2. Operative data

\begin{tabular}{lc}
\hline \multicolumn{1}{c}{ Variable } & Value \\
\hline Operation time (min, mean \pm SD) & $436 \pm 84$ \\
Cardiopulmonary bypass time (min, mean \pm SD) & $159 \pm 65$ \\
Circulatory arrest (min, mean \pm SD) & $5 \pm 13.7$ \\
Intraoperative temperature, $\left({ }^{\circ}\right.$ C, mean \pm SD) & $32.1 \pm 3.9$ \\
excluding hypothermia while circulatory arrest & \\
Reimplantation of intercostal or lumbar artery & $23(60.5 \%)$ \\
(patients, \%) & \\
No. of reimplanted intercostal or lumbar artery & $2 \pm 1.1$ \\
(mean \pm SD) & \\
Level TH 6 & 2 \\
Level TH 7 & 2 \\
Level TH 8 & 9 \\
Level TH 9 & 7 \\
Level TH 10 & 3 \\
Level TH 11 & 9 \\
Level TH 12 & 3 \\
Level L 1 & 9 \\
\hline
\end{tabular}

$S D$, Standard deviation; $T H$, thoracic; $L$, lumbar.

\section{Surgical Data}

The operative data are presented in Table 2. The mean operation time was $436 \pm 84$ minutes with a mean cardiopulmonary bypass duration of $159 \pm 65$ minutes. In 6 patients, deep hypothermic circulatory arrest for $5.0 \pm 13.7$ minutes was necessary. In $39.5 \%(n=15)$ of patients, there were no intercostal or lumbar arteries suitable for reattachment. The mean number of reimplanted intercostal and lumbar arteries was $2 \pm 1.1$. Cerebrospinal fluid drainage was used in all patients. The mean intraoperative body temperature was $32.1^{\circ} \mathrm{C} \pm 3.9^{\circ} \mathrm{C}$, excluding the temperature during circulatory arrest. One patient required extracorporeal membrane oxygenation for 8 days.

\section{Postoperative Outcome}

The postoperative data are summarized in Table 3. There were no intraoperative deaths, the 30-day mortality was $7.9 \%(\mathrm{n}=3)$, and the overall operative mortality was $10.5 \%(n=4)$. The causes of death were septic multipleorgan failure, bowel ischemia, and hypoxic brain injury in 1 patient each. Permanent paraplegia occurred in 3 patients $(7.9 \%)$ postoperatively, and no paraparesis was observed. The incidence of stroke was $7.9 \%(n=3) ; 2$ patients experienced complete regression of neurologic deficit before discharge. One of them experienced a stroke due to a heparin-induced thrombocytopenia. Nine patients $(23.7 \%)$ developed acute renal failure, of whom 4 $(10.5 \%)$ required temporary dialysis. Two patients required permanent hemodialysis at hospital discharge. One of them had already been dialyzed preoperatively.

Early postoperative complications included bleeding requiring reexploration in 2 patients $(5.3 \%)$ due to hemothorax and 2 patients $(5.3 \%)$ due to retroperitoneal 
TABLE 3. In-hospital outcome

\begin{tabular}{lc}
\hline \multicolumn{1}{c}{ Variable } & Value \\
\hline Operative mortality & $4(10.5 \%)$ \\
30-d mortality & $3(7.9 \%)$ \\
\hline Paraplegia & $3(7.9 \%)$ \\
Paraparesis & 0 \\
\hline Stroke & $3(7.9 \%)$ \\
Renal failure & $9(23.7 \%)$ \\
Requiring temporary dialysis & $4(10.5 \%)$ \\
Dialysis at discharge & $1(2.6 \%)$ \\
\hline Bleeding requiring re-thoracotomy & $2(5.3 \%)$ \\
Bleeding requiring laparotomy & $2(5.3 \%)$ \\
\hline Pneumonia & $4(10.5 \%)$ \\
Mechanical ventilation $>72$ h & $5(13.2 \%)$ \\
Tracheotomy & $4(10.5 \%)$ \\
Reintubation & $1(2.6 \%)$ \\
\hline Sepsis & $4(10.5 \%)$ \\
Wound infection requiring revision & $3(7.9 \%)$ \\
\hline Intensive care duration (d, median, IQR) & $3.5(2.3-21.5)$ \\
Duration of intubation (h, median, IQR) & $38(13-303.5)$ \\
\hline Hospital length of stay (d, median, IQR) & $21.5(16-38)$ \\
\hline
\end{tabular}

$I Q R$, Interquartile range.

hematoma and intra-abdominal bleeding. Bowel ischemia was encountered in 1 patient $(2.6 \%)$, who then received laparotomy and intestinal resection. Wound infection requiring surgical revision was observed in 3 patients $(7.9 \%)$. Vocal cord paralysis occurred in 1 patient $(2.6 \%)$. The median intensive care unit length of stay was 3.5 days (IQR, 2.321.5 days), and median hospital length of stay was 21.5 days (IQR, 16-38 days). The median duration of ventilation was 38 hours (IQR, 13.0-303.5 hours). Four patients developed pneumonia, and 4 others $(10.5 \%)$ required tracheotomy.

Emergency and urgent procedures did not significantly increase the incidence of spinal cord ischemia $(P=.369)$, stroke $(P=.748)$, or the 30-day mortality rates $(P=.369)$. Furthermore, chronic dissection (A and B) did not significantly influence the 30-day mortality and the occurrence of stroke and spinal cord ischemia. Connective-tissue disorders (Marfan syndrome, EhlersDanlos syndrome, Loeys-Dietz syndrome) had no bearing on early mortality and the incidence of neurologic deficits. More details about predictors of 30-day mortality are summarized in Table 4.

\section{Follow-up Data}

The mean follow-up time was $1.6 \pm 2$ years. At 1,3 , and 5 years after operation, the survival rates were $83 \%, 77 \%$, and $62 \%$, respectively (Figure 1). Age, gender, cardiopulmonary bypass time, diameter of aneurysm, extents I and II, and chronic aortic dissection were not predictors of mortality during the follow-up time. Likewise, intubation time, emergency procedures, the numbers of previous aortic procedures, and redo surgery could not be identified as predictors of overall mortality. Only preoperative renal insufficiency and prolonged postoperative noradrenalin support were identified as such (Table 5).

\section{DISCUSSION}

Various studies from high-volume centers for aortic surgery recognize the open surgical approach as the golden standard and set the benchmark for both other institutions and treatment options. ${ }^{3,6,11,12}$ Comparable reports from US or European "less-than-high-volume-centers" are relatively rare. ${ }^{7,13,14}$ Therefore, the aim of this study was to investigate the operative risk and postoperative course of open TAAA repair in a single, non-high-volume center. Open surgical TAAA repair is still associated with significant mortality and morbidity, with spinal cord injury being the most dreaded complication. ${ }^{2,15}$ We were able to show an acceptable rate of paraplegia at $7.9 \%$. Data series from centers with different volumes of aortic surgery reported rates of paraplegia between $2.9 \%$ and $12 \%$. ${ }^{2,4,6,13,15-17}$ Others demonstrated that the incidence of spinal cord injury is dependent on Crawford extent II. ${ }^{17,18}$ Extent II is already considered a predictor of early mortality. ${ }^{17,19,20}$ In our cohort among the 3 paraplegic patients, we observed 2 cases with extent II, 1 with previous aortic surgery, and 2 who underwent emergency surgery. Two of the 3 30-day deaths had extent II. In our aneurysm sample collective, extent II, extent I, emergency procedures, and redo surgery could not be identified as predictors of mortality and did not influence the occurrence of paraplegia significantly. In 23 of 38 patients $(60.5 \%)$, intercostal or lumbar arteries were reattached to the vascular graft. Three patients in our cohort developed paraplegia. Two of them did so despite intercostal or lumbar artery reimplantation. However, these 2 patients underwent emergency surgery and had presented with type II aneurysms. We regard both variables together as an important risk factor for the development of paraplegia despite intercostal or lumbar artery reimplantation. This aspect might have outweighed the beneficial effects of intercostal/lumbar artery reimplantation on spinal cord protection in these patients. ${ }^{21,22}$

Remarkably, the complex extent II was over-presented in our patient collective. This observation may be due to a shift of treatment allocation toward the endovascular approach in many patients with less complex aortic disease. In our cohort, we conducted 8 emergency procedures with a 30day mortality of $25 \%$ ( 2 of 330 -day deaths). Afifi and colleagues ${ }^{11}$ demonstrated that rupture at presentation was associated with $38.2 \%$ early mortality and that an 
TABLE 4. Thirty-day mortality, spinal cord ischemia, and stroke according to operation priority and pathology

\begin{tabular}{lcccc}
\hline & $\begin{array}{c}\text { No. of } \\
\text { patients }\end{array}$ & $\begin{array}{c}\text { 30-d } \\
\text { mortality }\end{array}$ & SCI & Stroke \\
\hline TAAA & & & & \\
$\quad$ Elective & 22 & 1 & 1 & 2 \\
Emergency/urgency & 16 & 2 & 2 & 1 \\
$\quad$ Chi-square & & $P=.369$ & $P=.369$ & $P=.748$ \\
Dissection & & & & \\
None & 14 & 2 & 2 & 0 \\
A & 12 & 1 & 0 & 1 \\
B & 12 & 0 & 1 & 2 \\
Chi-square & & $P=.403$ & $P=.403$ & $P=.29$ \\
Connective tissue disorder & & & & \\
$\quad$ No & 20 & 3 & 2 & 1 \\
$\quad$ Yes & 18 & 0 & 1 & 2 \\
Chi-square & & $P=.087$ & $P=.612$ & $P=.485$ \\
\hline
\end{tabular}

$S C I$, Spinal cord injury; TAAA, thoracoabdominal aortic aneurysm.

emergency operation was associated with early mortality of $53.3 \%$ in patients undergoing redo operation. Furthermore, Coselli and colleagues ${ }^{17}$ showed that emergency repair of TAAA was associated with a higher incidence of paraplegia and adverse outcome. ${ }^{23}$ Surprisingly, although all patients with connective-tissue disorders had undergone multiple surgical interventions previously and had chronic aortic dissections, they showed excellent outcome and no early deaths, and only 1 lethality during follow-up. Our findings were comparable to other studies that analyzed the mortality and outcome of patients with and without Marfan syndrome after TAAA repair. ${ }^{23-27}$ Therefore, we believe that open repair is preferable to endovascular treatment and remains the gold standard in these mostly young patients. The relatively large subcohort of patients with Marfan syndrome has shifted the mean age of our entire patient cohort to 54 years, which is more than 10 years younger

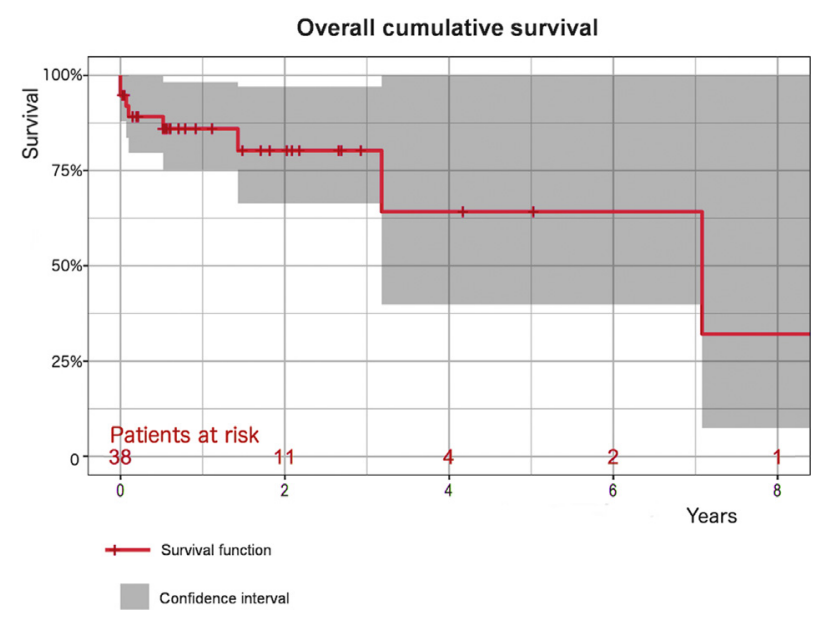

FIGURE 1. Survival of the cohort using Kaplan-Meier analysis including $95 \%$ confidence intervals and number of patients at risk.
TABLE 5. Cox proportional hazards regression analysis: Impact of certain risk factors on the overall mortality

\begin{tabular}{lcc}
\hline \multicolumn{1}{c}{ Variable } & OR, 95\% CI & $\boldsymbol{P}$ value \\
\hline Sex & .985 \\
\hline Age & .074 \\
\hline Redo surgery & .41 \\
\hline BMI & .42 \\
\hline Renal insufficiency & .003 \\
\hline CPB time & $.2(1.8-21.1)$ & .189 \\
\hline Crossclamp time & .294 \\
\hline Circulatory arrest & .43 \\
\hline Transfusion of packed red cells & .198 \\
\hline Operation time & .174 \\
\hline Noradrenalin - length of support & 1.1 (1.03-1.19) & .006 \\
\hline Intubation time & .155 \\
\hline Connective tissue disorder & .257 \\
\hline Urgent surgical indication & .438 \\
\hline Diameter of aneurysm & .98 \\
\hline Crawford I & .98 \\
\hline Crawford II & .561 \\
\hline Type A aortic dissection & .401 \\
\hline Type B aortic dissection & .678 \\
\hline Presence of stent graft & .526 \\
\hline Rethoracotomy & .545 \\
\hline OR, Odds ratio; $C I$, confidence interval; $B M I$, body mass index; $C P B$, cardiopulmo- \\
nary bypass. & \\
\hline
\end{tabular}

compared with other series. ${ }^{3,6,7,9}$ This aspect may have contributed to a relatively favorable early survival, because age has been identified as a predictor of mortality. Coselli and colleagues ${ }^{9}$ reported that the variable age at 50 years or younger was an independent predictor of reduced adverse events after open repair of TAAA. In accord with this finding, we observed no early deaths among patients with connective tissue disorders. Likewise, we were able to identify preoperative renal insufficiency as a risk factor of mortality. ${ }^{17}$ In addition, we found out that the postoperative need for prolonged noradrenalin support was an independent risk factor for overall mortality. To the best of our knowledge, this aspect has not been described before and may be indicative of additional comorbidities influencing the outcome.

There is increasing interest in the use of endovascular techniques as treatment of aortic pathologies. The respective results are acceptable but not significantly superior to open surgical repair of TAAA. The 30-day mortality is reported to be approximately $6.4 \%$ to $7.7 \%$, and the perioperative spinal cord ischemia is between $2.6 \%$ and $9.2 \%{ }^{4,28,29}$ Ferrer and colleagues ${ }^{4}$ demonstrated in a propensity-matched comparison that the 24 - and 42- 
month survival and rates of freedom from reintervention did not differ significantly between endovascular and open treatment of TAAAs. On the other hand, Verhoeven and colleagues $^{28}$ reported a 5 -year survival of approximately $66.6 \%$ after endovascular treatment. These results do not appear superior to the outcome after open repairs in highvolume centers. ${ }^{3,4,8,12,29}$ In addition, endovascular techniques have a significant incidence of specific complications, such as primary and secondary endoleaks, which make further interventions necessary. ${ }^{29}$

Another potential limitation of aortic endovascular therapy relates to anatomic and logistic issues, especially in emergency cases. ${ }^{30}$ Dias and colleagues ${ }^{31}$ reported a $28.6 \%$ rate of 30-day mortality in patients with ruptured TAAA after endovascular TAAA repair. These aspects add to the consideration that open surgery should remain the optimal treatment for ruptured descending thoracic aorta and TAAAs. ${ }^{7}$ In contrast to open repair, long-term follow-up beyond 10 years for the total endovascular repair of TAAA is still not available. ${ }^{11}$

Upon comparing the mortality and paraplegia rates of less-specialized centers with a high-volume center for aortic repair, we have observed differences that are probably acceptable. Nevertheless, the surgical experience remains an important issue. However, other published series with collectives of between 28 and 41 patients, as in our present study, also indicated comparable early mortality rates and paraplegia rates. ${ }^{13,14,32}$

\section{Study Limitations}

The study is limited by its design as a single-center retrospective review. Failure to demonstrate significant differences between patients who were operated on an elective or emergency basis could be related to the overall small number of patients in this cohort.

\section{CONCLUSIONS}

Contemporary, non-high-volume center reports regarding the outcomes of open surgical thoracoabdominal aortic replacement are extremely rare. Our results indicate mortality and complication rates comparable to those of high-volume centers. The finding supports the expectation that this treatment modality will remain the standard of care for the majority of patients including selected subcohorts with connective tissue disorders or other conditions such as endograft infection or adverse aortic anatomy unsuitable for endograft repair.

\section{Conflict of Interest Statement}

Authors have nothing to disclose with regard to commercial support.

\section{References}

1. Etheredge SN, Yee J, Smith JV, Schonberger S, Goldman MJ. Successful resection of a large aneurysm of the upper abdominal aorta and replacement with homograft. Surgery. 1955;38:1071-81.

2. LeMaire SA, Price MD, Green SY, Zarda S, Coselli JS. Results of open thoracoabdominal aortic aneurysm repair. Ann Cardiothorac Surg. 2012;1:286-92.

3. Murana G, Castrovinci S, Kloppenburg G, Yousif A, Kelder H, Schepens, et al. Open thoracoabdominal aortic aneurysm repair in the modern era: results from a 20-year single-centre experience. Eur J Cardiothorac Surg. 2016;49:1374-81.

4. Ferrer C, Cao P, De Rango P, Tshomba Y, Verzini F, Melissano G, et al. A propensity-matched comparison for endovascular and open repair of thoracoabdominal aortic aneurysms. J Vasc Surg. 2016;63:1201-7.

5. Zhang L, Zhao Z, Chen Y, Sun Y, Bao J, Jing Z, et al. Reintervention after endovascular repair for aortic dissection: a systematic review and meta-analysis. $J$ Thorac Cardiovasc Surg. 2016;152:1279-88.e3.

6. Coselli JS, LeMaire SA, Preventza O, de la Cruz KI, Cooley DA, Price MD, et al. Outcomes of 3309 thoracoabdominal aortic aneurysm repairs. J Thorac Cardiovasc Surg. 2016;151:1323-37.

7. Gaudino M, Lau C, Munjal M, Girardi LN. Open repair of ruptured descending thoracic and thoracoabdominal aortic aneurysms. J Thorac Cardiovasc Surg. 2015;150:814-21.

8. Schepens MA, Kelder JC, Morshuis WJ, Heijmen RH, van Dongen EP, ter Beek HT. Long-term follow-up after thoracoabdominal aortic aneurysm repair. Ann Thorac Surg. 2007;83:S851-5; discussion S890-2.

9. Coselli JS, Amarasekara HS, Green SY, Price MD, Preventza O, de la Cruz KI, et al. Open repair of thoracoabdominal aortic aneurysm in patients 50 years old and younger. Ann Thorac Surg. 2017;103:1849-57.

10. Wong DR, Parenti JL, Green SY, Chowdhary V, Liao JM, Zarda S, et al. Open repair of thoracoabdominal aortic aneurysm in the modern surgical era: contemporary outcomes in 509 patients. J Am Coll Surg. 2011;212:569-81.

11. Afifi RO, Sandhu HK, Trott AE, Nguyen TC, Miller CC, Estrera AL, et al. Redo thoracoabdominal aortic aneurysm repair: a single-center experience over 25 years. Ann Thorac Surg. 2017;103:1421-8.

12. Corvera J, Copeland H, Blitzer D, Hicks A, Manghelli J, Hess P, et al. Open repair of chronic thoracic and thoracoabdominal aortic dissection using deep hypothermia and circulatory arrest. J Thorac Cardiovasc Surg. 2017;154:389-95.

13. Kazen UP, Blohme L, Olsson C, Hultgren R. Open repair of aneurysms of the thoracoabdominal aorta. Thorac Cardiovasc Surg. 2016;64:275-80.

14. Folkmann S, Weiss G, Pisarik H, Czerny M, Grabenwoger M. Thoracoabdominal aortic aneurysm repair after frozen elephant trunk procedure. Eur J Cardiothorac Surg. 2015;47:115-9; discussion 119.

15. Jacobs MJ, de Mol BA, Legemate DA, Veldman DJ, de Haan P, Kalkman CJ. Retrograde aortic and selective organ perfusion during thoracoabdominal aortic aneurysm repair. Eur J Vasc Endovasc Surg. 1997;14:360-6.

16. Schepens MA, Heijmen RH, Ranschaert W, Sonker U, Morshuis WJ. Thoracoabdominal aortic aneurysm repair: results of conventional open surgery. Eur J Vasc Endovasc Surg. 2009;37:640-5.

17. Coselli JS, LeMaire SA, Conklin LD, Koksoy C, Schmittling ZC. Morbidity and mortality after extent II thoracoabdominal aortic aneurysm repair. Ann Thorac Surg. 2002;73:1107-16.

18. Jacobs MJ, Mommertz G, Koeppel TA, Langer S, Nijenhuis RJ, Mess WH, et al. Surgical repair of thoracoabdominal aortic aneurysms. J Cardiovasc Surg (Torino). 2007;48:49-58.

19. Coselli JS, LeMaire SA, Weldon SA. Extent II repair of thoracoabdominal aortic aneurysm secondary to chronic dissection. Ann Cardiothorac Surg. 2012;1: 394-7.

20. Aftab M, Songdechakraiwut T, Green SY, Zarda S, Price MD, Nalty CC, et al. Contemporary outcomes of open thoracoabdominal aortic aneurysm repair in octogenarians. J Thorac Cardiovasc Surg. 2015;149:S134-41.

21. Safi HJ, Miller CC, Carr C, Lliopoulos DC, Dorsay DA, Baldwin JC. Importance of intercostal artery reattachment during thoracoabdominal aortic aneurysm repair. J Vasc Surg. 1998;27:58-68.

22. Kuniyoshi Y, Koja K, Miyagi Shimoji M, Uezu T, Arakaki K, Yamashiro S, et al. Prevention of postoperative paraplegia during thoracoabdominal aortic surgery. Ann Thorac Surg. 2003; 76:1477-84.

23. Zanetti PP, Krason M, Walas R, Cebotaru T, Popa C, Vintila B, et al. Open repair of ruptured thoracoabdominal aortic aneurysm (experience of 51 cases). Kardiochir Torakochirurgia Pol. 2015;12:119-25.

24. Mommertz G, Sigala F, Langer S, Koeppel TA, Mess WH, Schurink GW, et al. Thoracoabdominal aortic aneurysm repair in patients with Marfan syndrome. Eur J Vasc Endovasc Surg. 2008;35:181-6. 
25. Kalkat MS, Rahman I, Kotidis K, Davies B, Bonser RS. Presentation and outcome of Marfan's syndrome patients with dissection and thoraco-abdominal aortic aneurysm. Eur J Cardiothorac Surg. 2007;32: $250-4$.

26. Coselli JS, Green SY, Price MD, Hash JA, Ouyang Y, Volguina IV, et al. Results of open surgical repair in patients with marfan syndrome and distal aortic dissection. Ann Thorac Surg. 2016;101:2193-201.

27. Ghanta RK, Green SY, Price MD, Arredondo CC, Wainwright D, Preventza $\mathrm{O}$, et al. Midterm survival and quality of life after extent II thoracoabdominal aortic repair in Marfan syndrome. Ann Thorac Surg. 2016;101: 1402-9.

28. Verhoeven EL, Katsargyris A, Bekkema F, Oikonomou K, Zeebregts CJ, Ritter W, et al. Editor's choice - ten-year experience with endovascular repair of thoracoabdominal aortic aneurysms: results from 166 consecutive patients. Eur J Vasc Endovasc Surg. 2015;49:524-31.
29. Vaaramaki S, Suominen V, Pimenoff G, Saarinen J, Uurto I, Salenius J. Long term experience of endovascular repair for thoracic aortic aneurysms and dissections. Vasc Endovascular Surg. 2016;50:335-42.

30. Melissano G, Mascia D, Atique SG, Bertoglio L, Chiesa R. Treatment of acute thoracoabdominal aortic aneurysms. J Cardiovasc Surg (Torino). 2017;58:228-37.

31. Dias NV, Sonesson B, Kristmundsson T, Holm H, Resch T. Short-term outcome of spinal cord ischemia after endovascular repair of thoracoabdominal aortic aneurysms. Eur J Vasc Endovasc Surg. 2015;49:403-9.

32. Mommertz G, Langer S, Koeppel TA, Schurink GW, Mess WH, Jacobs MJ. Brain and spinal cord protection during simultaneous aortic arch and thoracoabdominal aneurysm repair. J Vasc Surg. 2009;49:886-92.

Key Words: early mortality, open repair, outcomes, thoracoabdominal aneurysm

Readers who found these articles interesting may also like to read the following papers found in recent and future issues of our sister publications, Seminars in Thoracic and Cardiovascular Surgery and Operative Techniques in Thoracic and Cardiovascular Surgery!

\section{Adult: Aorta}

ORIGINAL SUBMISSION: Best Medical Treatment and Selective Stent-Graft Repair for Acute Type B Aortic Intramural Hematoma. Gabriele Piffaretti. Semin Thoracic Surg 2018: In press.

ORIGINAL SUBMISSION: Fluctuations in Spinal Cord Perfusion Pressure: A Harbinger of Delayed Paraplegia after Thoracoabdominal Aortic Repair. Harleen K. Sandhu. Semin Thoracic Surg 2017:451-459.

Editorial Commentary: Keep Alert Eyes on Delayed Paraplegia. Kenji Minatoya. Semin Thoracic Surg 2017:460-461.

Editorial Commentary: Problem Delayed Does Not Mean Solution Denied. Joseph S. Coselli. Semin Thoracic Surg 2017:462-463.

ORIGINAL SUBMISSION: Awake Thoracic Endovascular Aneurysm Repair for Aortic Rupture: A Case Series. Jessica Forcillo. Semin Thoracic Surg 2018:36-39.

Editorial Commentary: Awake TEVAR for Ruptured Thoracic Aneurysms: Less is More? Akiko Tanaka. Semin Thoracic Surg 2018:40-41. 